\title{
Measurement of Physical Fitness Employees Solo Net Surakarta
}

\author{
Baskoro Nugroho Putro1, Djoko Nugroho2, Budhi Satyawan', Sunardi', Waluyo ${ }^{5}$ \\ 1,2,3,4,5 Program Studi Pendidikan Jasmani Kesehatan dan Rekreasi, Fakultas Keolahragaan, \\ Universitas Sebelas Maret \\ Email: 1baskoro.np@staff.uns.ac.id \\ dc \\ https://doi.org/10.36526/gandrung.v2i1.1186
}

\begin{abstract}
Physical fitness is an essential aspect of life. The role of physical fitness in living life is limited to athletes and society in general. For workers, having a fit body will increase productivity because they do not feel tired quickly. Good physical fitness is supported by good endurance as well. However, endurance does not play a single role in supporting physical activity. Having good endurance is indeed beneficial and is a must for individuals involved in activities or work that take a long time. Please note that every activity or work has specific targets that must be completed. Other aspects must be possessed in order to become an individual with complete physical fitness. The demands of the quality of physical fitness in the general public certainly cannot be equated with athletes' standards. For the general public, not getting tired of doing work and meeting the targets given by the institution where they work is already extraordinary.
\end{abstract}

Keyword: Fitness, Sport, Productivity, Performance

\section{Pendahuluan}

Kebugaran jasmani merupakan aspek penting dalam kehidupan. Peran kebugaran jasmani dalam menjalani hidup tidak hanya terbatas pada atlet, tetapi juga pada masyarakat secara umum. Kebugaran jasmani didefinisikan sebagai kemampuan seseorang untuk melakukan kerja sehari-hari secara efisien tanpa menimbulkan kelelahan yang berarti sehingga masih dapat menikmati waktu luangnya (Kushartanti 2008). Memiliki kualitas fisik yang prima dipastikan pembangunan dalam segala sektor dapat tercapai secara optimal (Siregar 2010). Bagi para pekerja, kondisi tubuh yang bugar akan meningkatkan produktivitas karena tidak mudah merasa lelah.

Kebugaran jasmani yang baik ditunjang oleh daya tahan yang baik pula. Daya tahan dapat dikategorikan menjadi dua jenis, yaitu daya tahan aerobik yang menunjang seseorang untuk tahan beraktivitas fisik secara kontinyu dalam waktu yang lama dan daya tahan anaerobik yang menunjang seseorang untuk melakukan aktiftas berintensitas tinggi secara berulang-ulang (Bompa and Haff 2009). Hanya saja, daya tahan tidak berperan sendirian dalam menunjang aktivitas fisik. Memiliki daya tahan yang baik memang menguntungkan dan merupakan suatu keharusan bagi indvidu yang terlibat dalam kegiatan atau pekerjaan yang memakan waktu lama, tapi perlu diketahui bahwa setiap kegiatan atau pekerjaan memiliki target tertentu yang harus diselesaikan. Terdapat aspek lain yang juga harus dimiliki 
untuk menjadi individu dengan kebugaran jasmani yang lengkap. Hampir semua aktivitas fisik merupakan gabungan dari kekuatan, kecepatan, kelentukan, dan daya tahan (Bompa and Buzzichelli 2015).

Tuntutan kualitas kebugaran jasmani pada masyarakat umum tentunya tidak bisa disamakan dengan standar yang ditetapkan pada atlet. Bagi masyarakat umum, dalam hal ini orang yang memiliki pekerjaan dengan durasi yang cukup lama, tidak lelah dalam menjalani pekerjaan dan mampu memenuhi target yang diberikan oleh instansi tempat bekerja sudah merupakan hal yang luar biasa. Oleh karena itu, perlakuan yang diberikan juga berbeda. Perlakuan yang paling masuk akal untuk diaplikasikan adalah aktivitas yang tidak memakan banyak waktu dan dapat dilakukan ditempat kerja. Mitra kegiatan pengabdian adalah SOLO net yang merupakan perusahaan dalam bidang penyediaan jaringan internet, desain website, pengembangan software dan pelatihan hal terkait. Cakupan wilayah kerja dari SOLO net adalah Solo, Wonogiri, Sukoharjo, Karanganyar, Sragen, Boyolali, Klaten dan Magelang. Lebih lanjut tentang SOLO net dapat dicek melalui https://www.solonet.net.id/.

Aktivitas fisik yang terprogram diperlukan bagi seseorang yang bekerja di depan komputer dalam jangka waktu yang lama. Pekerjaan tersebut berpotensi masuk dalam kategori physical inactivity. Waktu yang dihabiskan untuk duduk dan bekerja dan merupakan bagian dari gaya hidup berhubungan dengan resiko kesehatan (Tremblay et al. 2010). Lebih lanjut lagi, obesitas dan penambahan berat badan merupakan dampak dari sedentary lifestyle dan kurangnya aktivitas fisik pada orang dewasa (MartinezGonzalez et al. 1999). Obesitas dan penambahan berat badan tersebut bisa dipengaruhi oleh sedentary lifestyle karena gaya hidup tersebut berhubungan dengan sindrom metabolisme (Lakka et al. 2003). Ritme dan tuntutan kerja pada karyawan SOLO net berpotensi besar untuk membuat para karyawan terkena penambahan berat badan dan berujung pada obesitas dikarenakan sindrom metabolisme yang merupakan akibat dari terlalu lama menghabiskan waktu untuk duduk di depan komputer.

\section{Metode}

Solusi yang direncanakan oleh tim pengabdi adalah aktivitas fisik rutin yang tidak membutuhkan banyak alat dan lokasi yang luas. Selain menentukan aktivitas fisik yang dilaksanakan juga dilakukan pengukuran keburagan jasmani untuk para karyawan agar dapat diketahui status kebugaran jasmani para karyawan tersebut. Tedapat beberapa item tes yang digunakan untuk mengukur kebugaran jasmani para karyawan. Berikut item tes dan cara pelaksanaan tes pengukuran yang digunakan (Mackenzie 2005):

Volume 2, Number 1, Februari 2021 | 92 
a. Indeks Massa Tubuh

1) Sarana dan Prasarana yang dibutuhkan:
a) Pengukur tinggi badan
b) Pengukur berat badan
c) Tempat datar dan dekat dengan tembok

2) Prosedur pelaksanaan tes:

a) Testee harus melepas alas kaki dan asesoris lainnya kecuali celan dan pakaian yang digunakan ketika melakukan pengukuran

b) Testee berdiri tegap dan menempel pada tembok ketika dilakukan pengukuran tinggi badan

c) Telapak kaki testee harus menempel sepenuhnya pada alat pengukur berat badan

d) Hasil pengukuran dihitung dengan menggunakan rumus:

$$
\text { IMT }=\frac{\text { Berat }(\mathrm{Kg})}{\text { Tinggi Badan }^{2} \text { (Meter) }}
$$

3) Norma tes indeks masa tubuh dapat dilihat pada Tabel 1.

Tabel 1. Norma Tes Indeks Masa Tubuh

b. Sit Up

\begin{tabular}{ll}
\hline Kategori & IMT \\
\hline Obesitas & $\geq 30,1$ \\
\hline Gemuk & $25-30$ \\
\hline Normal & $20-24,9$ \\
\hline Kurus & $\leq 19,9$ \\
\hline
\end{tabular}

1) Sarana dan Prasarana yang dibutuhkan:
a) Permukaan yang rata
b) Matras
c) Teman untuk menahan kaki

2) Prosedur pelaksanaan tes:
a) Berbaring diatas matras dengan lutut ditekuk, kaki menapak pada matras dan lengan menyilang di depan dada
b) Sit up dimulai dengan punggung menyentuh lantai
c) Angkat badan sampai minimal pada posisi $90^{\circ}$ dan kembali menyentuh lantai
d) Kaki dapat ditahan oleh teman
e) Lakukan sit up sebanyak mungkin selama 30 detik 
GANDRUNG: Jurnal Pengabdian Kepada Masyarakat ISSN: 2721-6136 (Online)

3) Norma tes sit up dapat dilihat pada tabel 2:

Tabel 2. Norma Tes Sit Up

\begin{tabular}{lcc}
\hline \multirow{2}{*}{ Kategori } & \multicolumn{2}{c}{ Jenis Kelamin } \\
\cline { 2 - 3 } & Laki-Laki & Perempuan \\
\hline Luar Biasa & $\geq 31$ & $\geq 26$ \\
\hline Baik & $26-30$ & $21-25$ \\
\hline Cukup & $20-25$ & $15-20$ \\
\hline Kurang & $17-19$ & $9-14$ \\
\hline Kurang Sekali & $\leq 16$ & $\leq 8$ \\
\hline
\end{tabular}

c. Push up

1) Sarana dan Prasarana yang dibutuhkan:

a) Permukaan yang rata

b) Matras

2) Prosedur pelaksanaan tes:

a) Berbaring diatas matras, posisi lengan dibuka selebar bahu dengan posisi siku tidak menekuk

b) Turunkan tubuh hingga pada posisi siku membentuk sudut $90^{\circ}$

c) Kembali pada posisi nomor 1

d) Untuk perempuan pada saat posisi push up dapat diganti dengan bertumpu pada lutut

3) Norma tes Push Up dapat dilihat pada Tabel 3 dan 4:

Tabel 3. Norma Tes Full Body Push Up

\begin{tabular}{llll}
\hline \multirow{2}{*}{ Kategori } & \multicolumn{3}{c}{ Usia } \\
\cline { 2 - 4 } & $20-29$ & $30-39$ & $40-49$ \\
\hline Full body Push up & & & $\geq 35$ \\
\hline Luar Biasa & $\geq 55$ & $\geq 45$ & $30-39$ \\
\hline Baik & $45-54$ & $35-44$ & $20-29$ \\
\hline Sedang & $35-44$ & $25-34$ & $12-19$ \\
\hline Cukup & $20-34$ & $15-24$ & $\leq 11$ \\
\hline Kurang & $\leq 19$ & $\leq 14$ &
\end{tabular}

Tabel 4. Norma Tes Full Body Push Up

\begin{tabular}{llll}
\hline \multirow{2}{*}{ Kategori } & \multicolumn{3}{c}{ Usia } \\
\cline { 2 - 4 } & $20-29$ & $30-39$ & $40-49$ \\
\hline Modified Push up & & & \\
\hline Luar Biasa & $\geq 49$ & $\geq 40$ & $20-34$ \\
\hline Baik & $34-48$ & $25-39$ & $8-19$ \\
\hline Sedang & $17-33$ & $12-24$ & $3-7$ \\
\hline Cukup & $6-16$ & $4-11$ &
\end{tabular}


GANDRUNG: Jurnal Pengabdian Kepada Masyarakat ISSN: 2721-6136 (Online)

\begin{tabular}{clll}
\hline \multirow{2}{*}{ Kategori } & \multicolumn{3}{c}{ Usia } \\
\cline { 2 - 4 } & $20-29$ & $30-39$ & $40-49$ \\
\hline Kurang & $\leq 5$ & $\leq 3$ & $\leq$ \\
\hline
\end{tabular}

d. Handgrip

1) Sarana dan prasaran yang dibutuhkan:

a) Handgrip dynamometer

2) Prosedur pelaksanaan tes:

a) Atur dynamometer pada angka 0

b) Sesuaikan ukuran handgrip dynamometer dengan ukuran tangan testee

c) Testee berdiri tegak menempel pada tembok

d) Testee memegang dynamometer secara vertikal di atas kepala

e) Ketika siap, testee menekan dynamometer sekeras mungkin.

f) Dilakukan pada kedua tangan

3) Norma tes handgrip:

Tabel 5. Norma Tes Handgrip

\begin{tabular}{ccc}
\hline \multirow{2}{*}{ Kategori $(\mathrm{kg})$} & \multicolumn{2}{c}{ Jenis Kelamin } \\
\cline { 2 - 3 } & Laki-Laki & Perempuan \\
\hline Luar Biasa & $\geq 65$ & $\geq 39$ \\
\hline Sangat Baik & $56-64$ & $34-38$ \\
\hline Atas Rata-rata & $52-55$ & $30-33$ \\
\hline Rata-rata & $48-51$ & $26-29$ \\
\hline Bawah Rata-rata & $44-47$ & $23-25$ \\
\hline Kurang & $40-43$ & $20-22$ \\
\hline Kurang Sekali & $\leq 39$ & $\leq 19$ \\
\hline
\end{tabular}

e. Sit and reach test

1) Sarana dan Prasarana yang dibutuhkan

a) Alat "sit and reach"

b) Tempat yang datar dan dekat dengan tembok

2) Prosedur pelaksanaan tes:

a) Posisi awal

1) Duduk di lantai dengan punggung menyandar pada tembok

2) Posisi tungkai lurus dan telapak kaki menempel pada alat

3) Letakkan tangan di alat pengukur dengan posisi tangan satu di atas tangan satunya dan 
GANDRUNG: Jurnal Pengabdian Kepada Masyarakat ISSN: 2721-6136 (Online)

siku lurus

b) Saat melakukan

1) Dorong alat pengukur kedepan dengan menggunakan jari secara perlahan dan diperbolehkan untuk menekuk punggung

2) Tahan posisi raihan maksimal selama 2 detik

3) Norma tes sit and reach:

Tabel 6. Norma Tes Sit and Reach

\begin{tabular}{|c|c|c|}
\hline \multirow{2}{*}{ Kategori } & \multicolumn{2}{|c|}{ Jenis Kelamin } \\
\hline & Laki-Laki & Perempuan \\
\hline Luar Biasa & $\geq 47 \mathrm{~cm}$ & $\geq 46 \mathrm{~cm}$ \\
\hline Baik & $38-46,5 \mathrm{~cm}$ & $38-45,5 \mathrm{~cm}$ \\
\hline Cukup & $27-37,5 \mathrm{~cm}$ & $29-37,5 \mathrm{~cm}$ \\
\hline Kurang & $17-26,5 \mathrm{~cm}$ & $20-28,5 \mathrm{~cm}$ \\
\hline Kurang Sekali & $\leq 16,5 \mathrm{~cm}$ & $\leq 19,5 \mathrm{~cm}$ \\
\hline
\end{tabular}

f. Multi-Stage Fitness Test

1) Sarana dan prasarana yang dibutuhkan dalam pelaksanaan adalah:

a) Tempat dengan permukaan datar dan tidak licin minimal sepanjang 20 meter

b) Cone sebagai penanda

c) Sound system

d) Lembar pencatat

2) Prosedur pelaksanaan tes:

a) Multi-Stage Fitness Test terdiri dari 22 level. Pergantian tiap level ditandai dengan bunyi beep tiga kali dan bunyi beep satu kali menunjukkan pergantian shuttle.

b) Testee mempersiapkan diri dengan melakukan peregangan dan joggging.

c) Testee harus menempatkan minimal kedua kaki sesudah garis penanda di setiap shuttle.

d) Jika testee sudah mencapai garis penanda sebelum ada bunyi beep, testee harus menunggu bunyi beep selanjutnya dan melanjutkan berlari.

e) Testee harus tetap berlari selama mungkin sampai tidak mampu mendahului irama bunyi beep.

f) Jika testee gagal untuk mencapai garis penanda sebelum bunyi beep sebanyak dua kali maka testee dianggap gugur dan harus berhenti mengikuti tes.

g) Setelah selesai melakukan tes, testee melakukan pendinginan.

3) Level dan norma pada Multi-Stage Fitness Test dapat dilihat di Tabel 7 dan 8: 
GANDRUNG: Jurnal Pengabdian Kepada Masyarakat ISSN: 2721-6136 (Online)

Tabel 7. Level dan shuttle

\begin{tabular}{|c|c|c|c|c|c|c|c|c|c|c|c|}
\hline Level & & & & & & & & & & 0 & 1 \\
\hline Shuttle & & & & & & 0 & 0 & 1 & 1 & 1 & 2 \\
\hline Level & 12 & 13 & 14 & 15 & 16 & 17 & 18 & 19 & 20 & 21 & 22 \\
\hline Shuttle & 12 & 13 & 13 & 13 & 14 & 14 & 15 & 15 & 16 & 16 & 17 \\
\hline
\end{tabular}

Tabel 8. Norma Penghitungan $\mathrm{VO}_{2} \max$

\begin{tabular}{lllll}
\hline \multirow{2}{*}{ Jenis Kelamin } & Kategori & Usia & & \\
\cline { 2 - 5 } & & $20-29$ & $30-39$ & $40-49$ \\
\hline \multirow{5}{*}{ Laki-laki } & Luar Biasa & $\geq 56$ & $\geq 52$ & $\geq 51$ \\
\cline { 2 - 5 } & Baik Sekali & $51-55$ & $48-53$ & $46-52$ \\
\cline { 2 - 5 } & Baik & $46-50$ & $44-47$ & $42-45$ \\
\cline { 2 - 5 } & Cukup & $42-45$ & $41-43$ & $38-41$ \\
\cline { 2 - 5 } & Kurang & $\leq 41$ & $\leq 40$ & $\leq 37$ \\
\hline \multirow{5}{*}{ Perempuan } & Luar Biasa & $\geq 50$ & $\geq 46$ & $\geq 43$ \\
\cline { 2 - 5 } & Baik Sekali & $44-49$ & $41-45$ & $39-44$ \\
\cline { 2 - 5 } & Baik & $40-43$ & $37-40$ & $35-38$ \\
\cline { 2 - 5 } & Cukup & $36-39$ & $34-36$ & $32-34$ \\
\cline { 2 - 5 } & Kurang & $\leq 35$ & $\leq 33$ & $\leq 31$ \\
\hline
\end{tabular}

Setelah pengukuran dilakukan dan diketahui hasilnya maka disusun jadwal aktivitas fisik. Aktivitas fisik yang dijadwalkan dapat dilakukan secara mandiri untuk hari senin dan rabu, sedangkan pada hari jumat aktivitas dilakukan secara terstruktur. Aktivitas fisik secara tersetruktur berfungsi sebagai sarana untuk melakukan pengecekan berkala apakah aktivitas mandiri dilakukan dengan baik atau tidak. Berikut gambaran aktivitas fisik yang direncanakan oleh tim pengabdi:

Tabel 9. Jenis Aktivitas Fisik yang Diprogramkan

\begin{tabular}{lccc}
\hline Hari & Durasi $^{*}$ & Jenis Aktivitas & Pelaksanaan \\
\hline Senin & $\begin{array}{c}20 \text { detik/aktivitas } \\
20 \text { detik istirahat antar } \\
\text { aktivitas }\end{array}$ & $\begin{array}{c}\text { Push up, Jumping Jack, Heel Touches, } \\
\text { Uneven Plank, Simple Squat, Mountain } \\
\text { Climber, Lunges, Standing Abs Twist }\end{array}$ & Mandiri \\
\hline Rabu & 60 Menit & Senam Aerobik ${ }^{* *}$ & Terstruktur \\
\hline Jumat & ${ }^{*}$ Tidak termasuk pemanasan dan pendinginan & \\
${ }^{* *}$ Dilakukan dengan arahan instruktur & &
\end{tabular}

a. Prosedur Aktivitas Hari Senin dan Rabu:

1. Lakukan pemanasan dan peregangan secara menyeluruh pada anggota badan.

2. Keseluruhan aktivitas merupakan 1 set 
3. Usahakan untuk melakukan 3 set pada 2 minggu awal sesuai dengan durasi yang ditentukan.

4. Naikan jumlah set setiap 2 minggu hingga mampu melakukan 6 set tanpa merasa lelah.

5. Lakukan tiap aktivitas dengan durasi 20 detik dan 20 detik untuk istirahat antar gerakan.

6. Jeda istirahat antar set adalah 3 menit.

7. Lakukan pendinginan setiap selesai melakukan aktivitas.

b. Penjelasan aktivitas:

1. Push Up

a) Mulai dengan dada menyentuh lantai, dengan tangan dibuka selebar bahu kaki rapat.

b) Ketika mulai mengangkat dan menurunkan badan, usahakan untuk posisi badan hingga kaki tetap lurus.

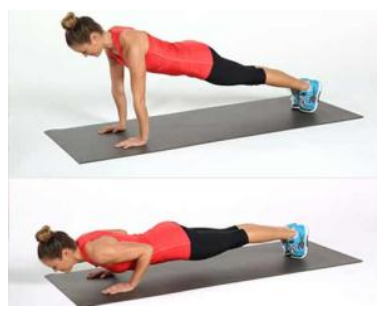

Gambar 2. Push Up

2. Jumping Jack

a) Berdiri tegap dengan kaki dibuka selebar bahu dan tangan berada di samping.

b) Meloncat ke atas setinggi mungkin dibarengi dengan mengangkat tangan ke atas.

c) Ketika selesai meloncat kembali pada posisi semula

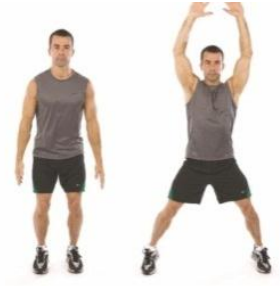

Gambar 3. Jumping Jack

3. Heel Touches

a) Mulai dengan posisi tidur telentang dan lutut ditekuk.

b) Usahakan kaki tetap menyentuh lantai dan rapat ketika melakukan.

c) Sentuh tumit kanan dan kiri secara bergantian dengan tangan.

d) Selama menyentuh tumit angkat kepala dan dada agar dapat menyentuh tumit dengan optimal.

Volume 2, Number 1, Februari 2021|98 


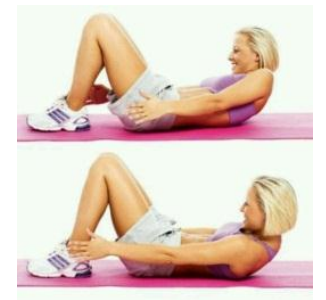

Gambar 4. Heel Touches

4. Uneven Plank

a) Mulai dengan posisi seperti push up.

b) Angkat badan dan tahan dengan cara siku kanan dan tangan kiri menyentuh lantai.

c) Lakukan dengan cara bergantian antara siku kiri dan tangan tangan begitu juga sebaliknya ketika menahan badan.

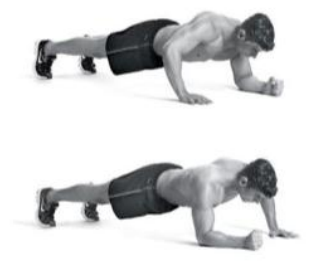

Gambar 5. Uneven Plank

5. Simple Squat

a) Mulai dengan posisi berdiri tegap.

b) Turunkan pinggul hingga sejajar dengan lutut dan lutut tidak boleh terdorong ke depan melebih jari kaki.

c) Naikan pinggul hingga berdiri tegap dan ulangi.

d) Taruh kedua tangan di depan untuk menyeimbangkan badan.

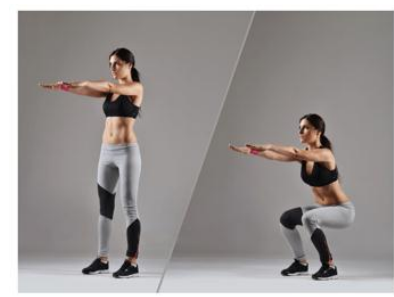

Gambar 6. Simple Squat

6. Mountain Climber

a) Mulai dengan posisi push up ketika mengangkat badan.

b) Angkat lutut secara bergantian mendekati siku. 


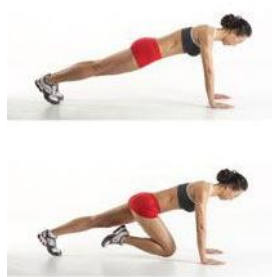

Gambar 7. Mountain Climber

7. Lunges

a) Mulai dengan posisi berdiri tegap.

b) Langkahkan kaki kanan dan kiri ke depan secara begantian hingga paha lurus.

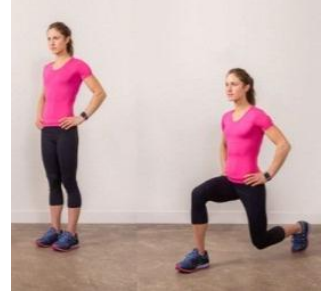

Gambar 8. Lunges

8. Standing Abs Twist

a) Mulai dengan posisi berdiri tegap dan kedua tangan berada dibelakang kepala dan siku terbuka.

b) Ayunkan lutut kiri ke arah siku kanan dan juga sebaliknya.

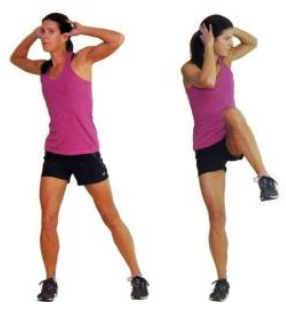

Gambar 9. Standing Abs Twist

\section{Hasil dan Diskusi}

Berdasarkan hasil pengukuran tersebut dapat dilihat bahwa dari 34 peserta tes (1 orang tidak mengikuti tes) hanya 1 peserta yang termasuk dalam kategori cukup dan selebihnya kurang. Detail hasil dapat pengukuran indeks massa tubuh dan pengukuran kebugaran jasmani dapat dilihat pada tabel 9 . Setelah melakukan pengukuran kebugaran jasmani pada karyawan maka didapat hasil sebagai berikut: 
GANDRUNG: Jurnal Pengabdian Kepada Masyarakat ISSN: 2721-6136 (Online)

Tabel 9. Hasil Pengukuran IMT dan Kebugaran Jasmani

\begin{tabular}{|c|c|c|c|c|c|c|c|c|c|c|c|c|c|c|c|}
\hline \multirow{2}{*}{ Inisial } & \multirow{2}{*}{ IMT } & \multicolumn{2}{|c|}{ Sit Up } & \multicolumn{2}{|c|}{ Push Up } & \multicolumn{4}{|c|}{ Handgrip } & \multicolumn{2}{|c|}{ Sit and Reach } & \multicolumn{2}{|c|}{ MFT } & \multicolumn{2}{|c|}{ Hasil Akhir } \\
\hline & & Hasil & Skor & Hasil & Skor & $\mathrm{Kn}$ & Skor & $\mathrm{Kr}$ & Skor & Hasil & Skor & Hasil & Skor & Rerata & Kategori \\
\hline A. S. & Normal & 17 & 2 & 14 & 1 & 32,7 & 1 & 34,1 & 1 & 39 & 4 & $4 / 3$ & 1 & 1,7 & Kurang \\
\hline B. W. & Obesitas & 24 & 3 & 13 & 1 & 32,3 & 1 & 34,6 & 1 & 34,6 & 3 & $2 / 4$ & 1 & 1,7 & Kurang \\
\hline B. & Gemuk & 19 & 2 & 16 & 1 & 47,7 & 2 & 46,7 & 1 & 30 & 3 & $3 / 4$ & 1 & 1,7 & Kurang \\
\hline D. H. & Kurus & 24 & 3 & 16 & 1 & 50,3 & 2 & 44,3 & 1 & 32,5 & 3 & $4 / 1$ & 1 & 1,8 & Kurang \\
\hline D. & Gemuk & 25 & 3 & 20 & 2 & 46,7 & 1 & 39,9 & 1 & 30 & 3 & $3 / 1$ & 1 & 1,8 & Kurang \\
\hline D. S. N. & Normal & 20 & 3 & 18 & 1 & 39,3 & 1 & 32,7 & 1 & 30 & 3 & $3 / 5$ & 1 & 1,7 & Kurang \\
\hline E. S. & Normal & 19 & 2 & 16 & 1 & 31,1 & 1 & 28,7 & 1 & 43,5 & 4 & $3 / 1$ & 1 & 1,7 & Kurang \\
\hline F.S. & Normal & 25 & 3 & 26 & 2 & 36 & 1 & 43,5 & 1 & 46 & 4 & $5 / 6$ & 1 & 2,0 & Kurang \\
\hline H. C. & Kurus & 18 & 2 & 17 & 1 & 38,7 & 1 & 32 & 1 & 39,5 & 4 & $4 / 9$ & 1 & 1,7 & Kurang \\
\hline I. & Normal & 23 & 3 & 22 & 2 & 34,4 & 1 & 35,1 & 1 & 24 & 2 & $4 / 8$ & 1 & 1,7 & Kurang \\
\hline I. & Obesitas & 10 & 1 & 16 & 1 & 45,9 & 1 & 48,8 & 2 & 32 & 3 & $2 / 2$ & 1 & 1,5 & Kurang \\
\hline K. M. & Normal & 25 & 3 & 22 & 2 & 48,7 & 2 & 43,6 & 1 & 40,5 & 4 & $4 / 4$ & 1 & 2,2 & Cukup \\
\hline M. A. & Normal & 23 & 3 & 23 & 2 & 40,3 & 1 & 29,2 & 1 & 44 & 4 & $3 / 3$ & 1 & 2,0 & Kurang \\
\hline M. Y. & Normal & 22 & 3 & 44 & 3 & 47,5 & 2 & 37,5 & 1 & 52 & 5 & $5 / 8$ & 1 & 2,5 & Cukup \\
\hline N.C.E. & Obesitas & 25 & 3 & 18 & 1 & 43,3 & 1 & 40,4 & 1 & 36 & 3 & $4 / 1$ & 1 & 1,7 & Kurang \\
\hline $\mathrm{R}$. & Kurus & 15 & 1 & 17 & 1 & 35,8 & 1 & 30,5 & 1 & 23,5 & 2 & $3 / 3$ & 1 & 1,2 & Kurang \\
\hline S. & Kurus & 12 & 1 & 15 & 1 & 25,3 & 1 & 27,1 & 1 & 19 & 2 & $4 / 9$ & 1 & 1,2 & Kurang \\
\hline S. S.P. & Obesitas & 20 & 3 & 18 & 1 & 32,6 & 1 & 37,5 & 1 & 31 & 3 & $3 / 1$ & 1 & 1,7 & Kurang \\
\hline S. S. & Normal & 23 & 3 & 11 & 1 & 31,1 & 1 & 26,1 & 1 & 28 & 3 & $3 / 3$ & 1 & 1,7 & Kurang \\
\hline S. I. & - & - & & - & & - & & - & & - & & - & & & \\
\hline S.P. & Gemuk & 16 & 1 & 14 & 1 & 31,9 & 1 & 36 & 1 & 34 & 3 & $3 / 1$ & 1 & 1,3 & Kurang \\
\hline S. & Gemuk & 13 & 1 & 8 & 1 & 41 & 1 & 44,6 & 1 & 32 & 3 & $3 / 1$ & 1 & 1,3 & Kurang \\
\hline W. H. & Kurus & 16 & 1 & 16 & 1 & 41,4 & 1 & 43,2 & 1 & 26,5 & 2 & $3 / 6$ & 1 & 1,2 & Kurang \\
\hline W. W. & Obesitas & 14 & 1 & 10 & 1 & 35,1 & 1 & 37,4 & 1 & 20 & 2 & $2 / 3$ & 1 & 1,2 & Kurang \\
\hline W. & Normal & 23 & 3 & 20 & 2 & 47,6 & 2 & 43,8 & 1 & 30 & 3 & $4 / 4$ & 1 & 2,0 & Kurang \\
\hline A. W. S. & Normal & 14 & 2 & 14 & 2 & 23,5 & 1 & 22,2 & 1 & 30 & 3 & $2 / 2$ & 1 & 1,7 & Kurang \\
\hline A. H. & Kurus & 10 & 2 & 12 & 2 & 23,2 & 1 & 14,1 & 1 & 35 & 3 & $2 / 5$ & 1 & 1,7 & Kurang \\
\hline C. E. & Normal & 14 & 2 & 14 & 2 & 25,7 & 1 & 27,6 & 2 & 34,5 & 3 & $2 / 3$ & 1 & 1,8 & Kurang \\
\hline C.S.H. & Normal & 9 & 2 & 13 & 2 & 17 & 1 & 20,3 & 1 & 18 & 1 & $2 / 1$ & 1 & 1,3 & Kurang \\
\hline L. V. & Normal & 18 & 3 & 17 & 3 & 20,7 & 1 & 20,4 & 1 & 27 & 2 & $2 / 4$ & 1 & 1,8 & Kurang \\
\hline M. C. T. & Normal & 13 & 2 & 14 & 2 & 17,8 & 1 & 22,2 & 1 & 23 & 2 & $2 / 3$ & 1 & 1,5 & Kurang \\
\hline
\end{tabular}


GANDRUNG: Jurnal Pengabdian Kepada Masyarakat ISSN: 2721-6136 (Online)

ANDRUNG

\begin{tabular}{|c|c|c|c|c|c|c|c|c|c|c|c|c|c|c|c|}
\hline \multirow{2}{*}{ Inisial } & \multirow{2}{*}{ IMT } & \multicolumn{2}{|c|}{ Sit Up } & \multicolumn{2}{|c|}{ Push Up } & \multicolumn{4}{|c|}{ Handgrip } & \multicolumn{2}{|c|}{ Sit and Reach } & \multicolumn{2}{|c|}{ MFT } & \multicolumn{2}{|c|}{ Hasil Akhir } \\
\hline & & Hasil & Skor & Hasil & Skor & $\mathrm{Kn}$ & Skor & $\mathrm{Kr}$ & Skor & Hasil & Skor & Hasil & Skor & Rerata & Kategori \\
\hline N. R. R. & Gemuk & 14 & 2 & 12 & 2 & 26,9 & 2 & 27,9 & 2 & 32 & 3 & $2 / 5$ & 1 & 2,0 & Kurang \\
\hline T. M. H. & Normal & 13 & 2 & 25 & 3 & 29,1 & 2 & 23,7 & 1 & 33 & 3 & $2 / 3$ & 1 & 2,0 & Kurang \\
\hline W. S. & Gemuk & 5 & 1 & 15 & 2 & 26,9 & 2 & 22,9 & 1 & 25,5 & 2 & $1 / 5$ & 1 & 1,5 & Kurang \\
\hline
\end{tabular}


GANDRUNG: Jurnal Pengabdian Kepada Masyarakat ISSN: 2721-6136 (Online)

Penentuan kategori pada hasil akhir berasal dari rata-rata skor dari tes sit up, push up, handgrip, sit and reach dan MFT. Norma yang digunakan pada hasil akhir terdiri dari 5 kategori. Skor 0-1 kategori kurang sekali, 1.1-2 kategori kurang, 2.1-3 kategori cukup, 3.1-4 kategori baik dan 4.1-5 kategori baik sekali. Skor tiap hasil tes berasal dari norma tiap tes yang terdiri dari 5 kategori. Kategori tertinggi mendapatkan skor 5 dan terendah mendapatkan skor 1. Indeks massa tubuh tidak dilakukan penskoran karena digunakan sebagai informasi tambahan yang berdiri-sendiri. Indeks massa tubuh digunakan untuk memprediksi kesehatan karyawan SOLO net. Orang dengan berat badan yang tidak ideal, terutama berlebih, memiliki resiko kematian dini, terjangkit penyakit tidak menular dan mempengaruhi pencapaian dalam hidup (Paulitsch and Dumith 2021; Gaydosh and McLanahan 2021).

Tiap kategori pada hasil akhir merupakan gambaran dari kondisi fisik karyawan SOLO net. Kategori kurang sekali memiliki arti karyawan memiliki kebugaran yang sangat buruk dan berpotensi tidak produktif karena tidak memiliki ketahanan untuk bekerja dalam waktu yang lama. Seiring dengan membaiknya kategori, dengan kategori sangat baik sebagai kategori paling atas, karyawan dianggap memiliki kebugaran dan produktiftas yang sangat baik. Kebugaran dan produktifitas yang baik akan membantu perusahan SOLO net untuk berkembang menjadi perusahaaan yang lebih baik lagi. Berdasarkan hasil dari pengukuran kebugaran jasmani, diperlukan aktivitas fisik yang dapat dilakukan dengan mudah. Solusi yang direncanakan oleh tim pengabdi adalah aktivitas fisik rutin yang tidak membutuhkan banyak alat dan lokasi yang luas. Selain menentukan aktivitas fisik yang dilaksanakan juga dilakukan pengukuran keburagan jasmani untuk para karyawan agar dapat diketahui status kebugaran jasmani para karyawan tersebut.

Terkait dengan program aktivitas yang dirancang oleh tim pengabdi, program tersebut tidak membutuhkan waktu yang lama mengingat dilakukan pada waktu sebelum melakukan pekerjaan. Program yang disusun terdiri dari 1 set gerakan yang berisi 8 gerakan, gerakan tersebut melatih otot lengan, perut dan tungkai secara bergantian. Durasi melakukan dan istirahat dibuat dengan dosis 1:1 agar daya tahan jantung paru juga dapat dilatih. Tiap gerakan dilakukan selama 20 detik dengan waktu istirahat 20 detik. Pada minggu pertama karyawan diharapkan bisa menyelesaikan minimal 3 set dengan jeda antar set sebanyak 3 menit. Program yang diterapkan pada karyawan mengadopsi metode HIIT atau High Intensity Interval Training. HIIT terbukti dapat digunakan untuk menaikan volume oksigen maksimal dan daya tahan pada otot (Salazar-Martínez et al. 2018). Kegiatan senam aerobik pada karyawan bertujuan untuk menghindari kebosanan dan stres. Aktivitas HIIT secara terus menerus menjadi latihan yang melelahkan dan cenderung memberi pengaruh buruk secara psikologi (Faruk Ugras 2013; Selmi et al. 2018).

Volume 2, Number 1, Februari 2021| 103 
GANDRUNG: Jurnal Pengabdian Kepada Masyarakat ISSN: 2721-6136 (Online)

\section{Kesimpulan}

Melihat kebugaran jasmani yang hampir seluruhnya kurang maka dapat disimpulkan bahwa karyawan SOLO net kurang dalam melakukan aktivitas fisik yang menunjang kebugaran jasmani. Terlebih lagi dari hasil pengukuran Indeks Masa Tubuh hanya terdapat 16 peserta yang memiliki IMT normal, selebihnya kurus, gendut dan 1 peserta obesitas. Selain kebugaran tampaknya nutrisi juga menjadi masalah yang harus diperhatikan oleh karyawan solo net.

Selain kebugaran, IMT juga dapat dijadikan indikator kesehatan dan resiko yang mungkin dapat diperoleh karyawan ke depannya. Karyawan dengan IMT kategori gendut dan obesitas diprediksi tidak mampu mengontrol pola makan mereka. Seperti yang kita ketahui pola makan yang tidak teratur merupakan salah satu sumber penyakit. Oleh karena itu aktivitas fisik selain untuk menjaga atau meningkatkan kebugaran juga digunakan untuk mengontrol indeks masa tubuh.

\section{Daftar Referensi}

Bompa, Tudor O., and Carlo A. Buzzichelli. (2015). Periodization Training for Sports. 3rd ed. Human Kinetic.

Bompa, Tudor O., and G. Gregory Haff. (2009). Periodization: Theory and Methodology of Training. Forth Edit. New York: Kendal/Hunt Publishing Company.

Faruk Ugras, A. (2013). "Effect of High Intensity Interval Training on Elite Athletes' Antioxidant Status." Science and Sports 28 (5): 253-59. https://doi.org/10.1016/j.scispo.2012.04.009.

Gaydosh, Lauren, and Sara McLanahan. (2021). "Youth Academic Achievement, Social Context, and Body Mass Index." SSM - Population Health 13. https://doi.org/10.1016/j.ssmph.2020.100708.

Kushartanti, Wara. (2008). "Kebugaran Jasmani Dan Produktivitas Kerja." Yogyakarta.

Lakka, Timo A., David E. Laaksonen, Hanna-Maaria Lakka, Niko Mannikko, Leo K. Niskanen, Rainer Rauramaa, and Jukka T. Salonen. (2003). "Sedentary Lifestyle , Poor Cardiorespiratory Fitness, and the Metabolic Syndrome." Medicine \& Science in Sports \& Exercise, 1279-86. https://doi.org/10.1249/01.MSS.0000079076.74931.9A.

Mackenzie, Brian. (2005). 101 Performance Evaluation Tests. Jonathan Pye.

Martinez-Gonzalez, M. A., J. Alfredo Martinez, F. B. Hu, M. J. Gibney, and J. Kearney. (1999). "Physical Inactivity , Sedentary Lifestyle and Obesity in the European Union." International Journal of Obesity.

Paulitsch, Renata G., and Samuel C. Dumith. (2021). "Is Food Environment Associated with Body Mass Index, Overweight and Obesity? A Study with Adults and Elderly Subjects from Southern Brazil." 
GANDRUNG: Jurnal Pengabdian Kepada Masyarakat ISSN: 2721-6136 (Online)

$\begin{array}{lllll}\text { Preventive } & \text { Medicine } & \text { Reports } 21 & \text { (December } & \end{array}$ https://doi.org/10.1016/j.pmedr.2021.101313.

Salazar-Martínez, Eduardo, Alfredo Santalla, José Naranjo Orellana, Jochen Strobl, Martin Burtscher, and Verena Menz. (2018). "Influence of High-Intensity Interval Training on Ventilatory Efficiency in Trained Athletes." Respiratory Physiology and Neurobiology 250 (November 2017): 19-23. https://doi.org/10.1016/j.resp.2018.01.016.

Selmi, O., W. Ben khalifa, M. Zouaoui, F. Azaiez, and A. Bouassida. (2018). "High Intensity Interval Training Negatively Affects Mood State in Professional Athletes." Science and Sports 33 (4): e15157. https://doi.org/10.1016/j.scispo.2018.01.008.

Siregar, Yan Indra. (2010). "Peranan Kebugaran Jasmani Dalam Meningkatkan Kinerja." Jurnal Pengabdian Kepada Masyarakat 16 (60): 77-83.

Tremblay, Mark Stephen, Rachel Christine Colley, Travis John Saunders, Genevieve Nissa Healy, and Neville Owen. (2010). "Physiological and Health Implications of a Sedentary Lifestyle" 740: 72540. https://doi.org/10.1139/H10-079. 